\title{
Electrochemical and Scanning Force Microscopy Characterization of Fractal Palladium Surfaces Resulting from the Electroreduction of Palladium Oxide Layers
}

\author{
T. Kessler, ${ }^{\dagger}$ A. Visintin, A. E. Bolzan, G. Andreasen, R. C. Salvarezza, \\ W. E. Triaca, and A. J. Arvia* \\ Instituto de Investigaciones Fisicoquímicas Teóricas y Aplicadas (INIFTA), Universidad \\ Nacional de La Plata, Sucursal 4, Casilla de Correo 16, (1900) La Plata, Argentina
}

Received May 30, $1996^{\otimes}$

\begin{abstract}
Pd oxide layers were grown by applying to smooth Pd electrodes a potential reversal technique (PRT) in $1 \mathrm{M} \mathrm{H}_{2} \mathrm{SO}_{4}$ at $25^{\circ} \mathrm{C}$. The electroreduction of the $\mathrm{Pd}$ oxide layer was made either voltammetrically or potentiostatically, yielding a Pd overlayer with a large increase in surface area. The effective range of PRT conditions for increasing the Pd surface area was established. The increase in surface area of treated Pd was voltammetrically determined. The electrochemical behavior of treated Pd electrodes in acid revealed an enhancement of the $\mathrm{H}$ atom surface electroadsorption processes. This behavior is consistent with the fractal characteristics of the treated Pd electrode surface, as demonstrated by the analysis of scanning force microscopy imaging data.
\end{abstract}

\section{Introduction}

Hydrous oxide films on noble metals have been most commonly achieved under potential cycling. ${ }^{1-4}$ The growth of these films has been studied over the years because of their possible applications in many areas of physical chemistry including oxide layer properties, the corrosion and passivation of metals, and heterogeneous catalysis and electrocatalysis. Previous studies of the electrochemical oxidation of noble metals ${ }^{1-12}$ have suggested that hydrous metal oxide layers ( $\beta$-oxide) are formed above a compact, anhydrous metal oxide layer ( $\alpha$-oxide), although the exact composition and structure of these layers continue to be a matter of research..$^{3,8}$

In the past decades, the application of a potential reversal technique (PRT) consisting of a square wave potential routine has made it possible to modify the surface of a number of polycrystalline metals to produce faceting at $\mathrm{Pt}^{1,13}$ and $\mathrm{Pd}$ electrodes, ${ }^{14}$ and to grow oxide layers on $\mathrm{Pt},{ }^{1} \mathrm{Au},{ }^{15} \mathrm{Ni},{ }^{7} \mathrm{Co}^{16}$ and amorphous alloy electrodes. ${ }^{17} \mathrm{The}$ predominant effect resulting from this type of electro-

${ }^{\dagger}$ Present address: Facultad de Ingeniería, UNCPBA, C. C. 12 (7400) Olavarría, Argentina.

${ }^{\otimes}$ Abstract published in Advance ACS Abstracts, December 1, 1996.

(1) Chialvo, A. C.; Triaca, W. E; Arvia, A. J. J. Electroanal. Chem. 1983, 146, 93. 139.

(2) Burke, L. D.; Roche, M. B. C. J. Electroanal. Chem. 1985, 186,

(3) Burke, L. D.; Lyons, M. E. G. In Modern Aspects of Electrochemistry; White, R. E., Bockris, J. O’M., Conway, B. E., Eds.; Plenum Press: New York, 1986; Vol. 18, Chapter 4, p 169.

(4) Arvia, A. J.; Canullo, J. C.; Custidiano, E.; Perdriel, C. L.; Triaca, W. E. Electrochim. Acta 1986, 31, 1359.

(5) Burke, L. D.; Casey, J. K. J. Appl. Electrochem. 1993, 23, 573.

(6) Burke, L. D.; Casey, J. K. J. Electrochem. Soc. 1993, 140, 1284.

(7) Visintin, A.; Chialvo, A. C.; Triaca, W. E.; Arvia, A. J. J. Electroanal. Chem. 1987, 225, 227.

(8) Zhang, A. J.; Gaur, M.; Birss, V. I. J. Electroanal. Chem. 1995, 389, 149.

(9) Burke, L. D.; Buckley, D. T. J. Electrochem. Soc. 1996, 143, 845

(10) Burke, L. D. Electrochim. Acta 1994, 39, 1841.

(11) Belanger, G.; Vijh, A. K. In Oxide and Oxide Films; Vijh, A. K.,

Ed.; M. Dekker: New York, 1977; Vol. 5, Chapter 1, p 1.

(12) Burke, L. D. In Electrodes of Conductive Metallic Oxides; Trasatti,

S., Ed.; Elsevier: New York, 1980; Part. A, Chapter 3, p 141.

(13) Visintin, A.; Canullo, J. C.; Triaca, W. E.; Arvia, A. J. J. Electroanal. Chem. 1988, 239, 67.

(14) Perdriel, C. L.; Custidiano, E.; Arvia, A. J. J. Electroanal. Chem 1988, 246, 165.

(15) Vela, M. E.; Salvarezza, R. C.; Arvia, A. J. Electrochim. Acta 1990, 35, 117. chemical treatment depends on (i) the specific characteristics of the metal/solution interface, such as the rate of metal electrodissolution/electrodeposition, and the solubility and properties of the anodically formed products, and (ii) the characteristics of the periodic potential routine itself, i.e., its waveform, upper and lower potential limits, frequency, and the anodic-to-cathodic half-period ratio which determines the waverform symmetry.

For Pt electrodes in acidic solution, changes in either the real surface area or the distribution of crystallographic faces produced by either repetitive square or triangular potential routines have been systematically investigated using both symmetric and asymmetric signals. ${ }^{1,13,18}$ Conversely, for $\mathrm{Pd}$ electrodes, the growth of oxide layers promoted by potential cycling has been examined in both acidic and basic media employing switching potentials in the range $0.5-2.8 \mathrm{~V}$ over a large frequency range. ${ }^{6,8,9}$

The various complex electrochemical reactions occurring during the oxidation-reduction cycling of $\mathrm{Pd}$ electrodes in acidic solution produce, under certain conditions, a substantial increase in the real surface area and afterward the treated Pd surface in contact with the acidic solution exhibits a reproducible and well-defined voltammetric behavior for the $\mathrm{H}$-atom electroadsorption reactions. Therefore, this type of Pd surface becomes particularly interesting from the standpoint of both electrocatalysis and the possible modification of the rate of $\mathrm{H}$-atom charging into $\mathrm{Pd} .{ }^{14}$

The purpose of this work is to establish the adequate range of PRT conditions to achieve a large electrochemically active surface area of Pd in acidic solution and to relate the increase in the active surface area to the enhancement of $\mathrm{H}$ atom surface processes which has been observed under certain circumstances on $\mathrm{Pd}$ electrodes. ${ }^{14,19-25}$ From electrochemical and scanning force microscopy imaging data, the increase in the relative

(16) Kessler, T.; Visintin, A.; Chialvo, M. R. G. de; Triaca, W. E. Arvia, A. J. J. Electroanal. Chem. 1989, 261, 315.

(17) Kessler, T.; Triaca, W. E.; Arvia, A. J. J. Appl. Electrochem. 1993, 23, 655 .

(18) Triaca, W. E.; Kessler, T.; Canullo J. C.; Arvia, A. J. J. Electrochem. Soc. 1987, 134, 1165.

(19) Tateishi, N.; Yahikozawa, K.; Nishimura, K.; Takasu, Y. Electrochim. Acta 1992, 37, 2427.

(20) Baldauf, M.; Kolb, D. M. Electrochim. Acta 1993, 38, 2145.

(21) Shimazu, K.; Kita, H. J. Catal. 1983, 83, 407.

(22) Harris, L. A. J. Electrochem. Soc. 1982, 129, 2689. 
contribution of H-atom surface processes to the overall hydrogen electrode reaction on Pd in acidic solution can be explained on the basis of the fractal properties of treated $\mathrm{Pd}$ surfaces. The formation of a Pd fractal surface from the electroreduction of the Pd oxide layer accumulated by the PRT treatment is consistent with a Pd layer growth mechanism leading to a columnar-like metal surface topography.

\section{Experimental Section}

Runs were carried out in aqueous $1 \mathrm{M} \mathrm{H}_{2} \mathrm{SO}_{4}$, at $25^{\circ} \mathrm{C}$, using a conventional three-electrode cell. Palladium wire (J. Matthey Chem. Co., spec pure) working electrodes $0.5 \mathrm{~mm}$ in diameter were used. A large platinum sheet acted as counterelectrode and a reversible hydrogen electrode immersed in the same solution was the reference electrode. First, the working electrodes were carefully polished with $0.03 \mu \mathrm{m}$ grit alumina and rinsed repeteadly with Milli-Q* water and electrolyte solution. Then, the surface was modified by applying a PRT under controlled conditions. The values of the upper, $E_{\mathrm{u}}$, and lower, $E_{1}$, potential limits, the frequency, $f$, and the duration of each potential step, $\tau_{\mathrm{u}}$ and $\tau_{1}$, were adjusted at convenience. The ratio $\tau_{\mathrm{u}} / \tau_{1}=1$ or $\tau_{\mathrm{u}} / \tau_{1}$ $\neq 1$ determined the symmetry or the asymmetry of the waveform, respectively. Further details of this procedure have been described elsewhere. ${ }^{7}$

The basic procedure for the accumulation of the Pd oxide layer consisted of the application of PRT using the following range of conditions: $-0.1 \mathrm{~V} \leq E_{\mathrm{l}} \leq 0.3 \mathrm{~V} ; 1.6 \mathrm{~V} \leq E_{\mathrm{u}} \leq 1.9 \mathrm{~V}, 0.1 \mathrm{kHz} \leq$ $f \leq 5 \mathrm{kHz} ; 0.1 \leq \tau_{\mathrm{u}} / \tau_{1} \leq 10$. The duration of the PRT treatment was extended within the range $3 \mathrm{~s} \leq t_{\mathrm{prt}} \leq 25 \mathrm{~min}$. Thus, the most adequate range of PRT conditions for Pd oxide layer accumulation was established in terms of its average thickness calculated from the oxide layer charge.

Once the Pd oxide layer was formed, two different electroreduction procedures were employed, either a potentiostatic electroreduction at $E=0.40 \mathrm{~V}$ or a single linear potential sweep electroreduction in the range $0.002 \mathrm{~V} / \mathrm{s} \leq V \leq 0.1 \mathrm{~V} / \mathrm{s}$. In the former case, the potentiostatic current transient was recorded, whereas in the latter the electroreduction voltammogram was obtained.

Cyclic voltammograms run with Pd electrodes resulting from the Pd oxide layer electroreduction showed a decrease in the voltammetric charge during the repetitive potential cycling, although a limiting stabilized voltammogram was approached after a certain number of cycles.

To make the stabilization of the Pd electrode surface faster, a potential cycling between 0.15 and $1.3 \mathrm{~V}$ at $V=0.005 \mathrm{~V} / \mathrm{s}$ was applied to the Pd electrode for a time $t_{\mathrm{v}} \geq 10 \mathrm{~min}$. Stabilized Pd electrodes - hereafter denoted as treated Pd electrodes-were used in this work.

Further experiments comprised the application of either triangular (TMTPS) or linear (TMLPS) modulated potential scans. These techniques consisted basically of applying a relatively slow potential scan, either single or repetitive, modulated by a fast triangular potential scan of small amplitude. In this way, the different electrochemical processes could be discriminated by changing the frequency of the fast potential perturbation. Both TMTPS and TMLPS have been succesfully applied to the study of adsorbed intermediates produced during an electrochemical reaction. ${ }^{26-29}$ In this work, by adjusting the amplitude $(A)$ of the modulating signal to $0.040 \mathrm{~V}$, and the modulation frequency $(f)$ at $2 \mathrm{kHz}$, it was possible to distinguish the $\mathrm{H}$ and $\mathrm{OH}$ electrosorption processes on $\mathrm{Pd}$.

(23) Chevillot, J. P.; Farcy, J.; Hinnen, C.; Rousseau, A. J. Electroanal. Chem. 1975, 64, 39.

(24) Czerwinski, A.; Marassi, R.; Zamponi, S. J. Electroanal. Chem. 1991, 316, 211 373.

(25) Czerwinski, A.; Marassi, R. J. Electroanal. Chem. 1992, 322,

(26) Conway, B. E.; Angerstein-Kozlowska, H.; Ho, F. C.; Klinger, J.; MacDougall, B.; Gottesfeld, S. Discuss. Faraday Soc. 1973, 56, 210.

(27) Tacconi, N. R. de; Zerbino J. O.; Arvia, A. J. J. Electroanal. Chem. 1977, 79, 287.

(28) Zerbino, J. O.; Tacconi, N. R. de; Arvia, A. J. J. Electrochem. Soc. 1978, $125,1266$.

(29) Bolzan, A. E.; Chialvo, A. C.; Arvia, A. J. J. Electroanal.Chem. 1984, 179,71 .

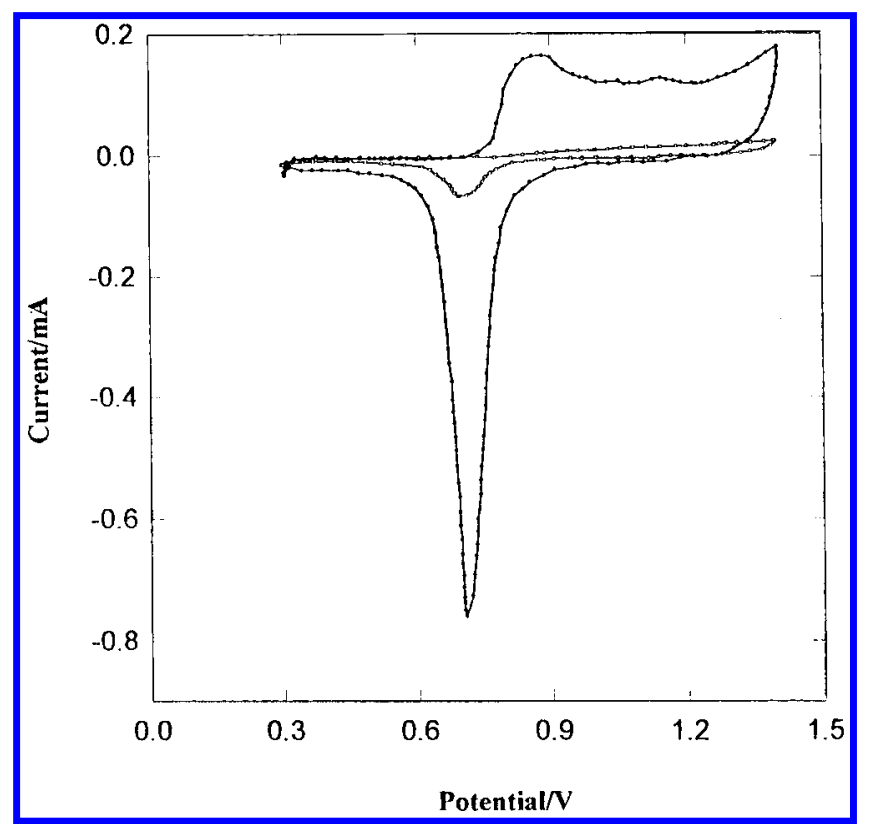

Figure 1. Voltammograms run at $0.1 \mathrm{~V} / \mathrm{s}$ in $1 \mathrm{M} \mathrm{H}_{2} \mathrm{SO}_{4}, 25^{\circ} \mathrm{C}$, for $(\bigcirc)$ smooth Pd, and $(\bullet)$ treated Pd $(R=9) . E_{\mathrm{l}}=0 \mathrm{~V} ; E_{\mathrm{u}}=$ $1.7 \mathrm{~V}, f=1 \mathrm{kHz} ; \tau_{\mathrm{u}} / \tau_{1}=9, t_{\mathrm{prt}}=3 \mathrm{~min}$.

A conventional setup was used in the electrochemical experiments made with both smooth and treated Pd. The modulated voltammograms were recorded on a Kenwood Model CS-5130 oscilloscope and the photographic displays were obtained with a Nikon FE2 camera using Ilford FP4 film.

Scanning force microscopy (SFM) images of smooth and treated Pd electrode topography were obtained using a Nanoscope III AFM equipment (Digital Instruments, Santa Barbara, CA) mounted on an optical microscope (Optizoom, Nikon, available from Digital Instruments). This assembly was very useful in locating the regions in which the SFM images were subsequently taken. SFM imaging was made using the $j$ head (maximum scan size $160 \mu \mathrm{m}$ ). Integral $\mathrm{Si}_{3} \mathrm{~N}_{4}$ tips mounted onto gold-coated cantilevers (Digital Instruments) were employed. Typical forces used for imaging were in the range of $10 \mathrm{nN}$. All SFM images were taken in the contact force mode. SFM calibration was performed by imaging a mica test surface. At the highest resolution the typical hexagonal array with the interatomic distance $d=0.55 \mathrm{~nm}$ was imaged.

\section{Results}

3.1. Voltammetric Characteristics Used for the Evaluation of the Relative Increase in the Pd Electrode Surface Area. A voltammogram of smooth $\mathrm{Pd}$ in aqueous $1 \mathrm{M} \mathrm{H}_{2} \mathrm{SO}_{4}$ after 10 min potential cycling at $0.1 \mathrm{~V} / \mathrm{s}$ between 0.3 and $1.4 \mathrm{~V}$ (Figure 1) shows in the positive-going potential scan an anodic current quasiplateau extending from ca. $0.85 \mathrm{~V}$ upwards, and in the reverse scan a cathodic current peak at ca. $0.7 \mathrm{~V}$, as earlier reported. ${ }^{30}$ The voltammetric charges have been assigned to the electroformation and electroreduction of an Ocontaining layer on $\mathrm{Pd}$, presumably close to a one $\mathrm{O}$ atom monolayer (ML) thickness. ${ }^{31,33}$ It should be noted that the starting potential was chosen sufficiently positive to prevent as far as possible $\mathrm{Pd}-\mathrm{H}$ chemical interactions, and the upper potential was set lower than the potential at which both direct oxidation of $\mathrm{Pd}$ to $\mathrm{Pd}(\mathrm{IV})$, and the interference of the oxygen evolution reaction could be produced.

(30) Woods, R. In Electroanalytical Chemistry, Bard, A. J., Ed.; M. Dekker: New York, 1977; Vol. 9, p 1.

(31) Breiter, M. W. J. Electroanal. Chem. 1977, 81, 275.

(32) Cherchie, T.; Mayer, C.; Lorenz, W. J. J. Electroanal. Chem. 1982, 135, 211.

(33) Gossner, K.; Mizera, E. J. Electroanal. Chem. 1981, 125, 347

(34) Thirsk, H. R.; Harrison, J. A. A Guide to the Study of Electrode Kinetics; Academic Press: London, 1972; p 62. 
A voltammogram resulting from a treated Pd electrode run under similar conditions (Figure 1) practically reproduces the features already described for smooth $\mathrm{Pd}$, except for a substantial increase in the voltammetric charge and a better definition in the anodic current profile. The functionalities of the electroreduction current peak fit the predictions of an irreversible surface electrochemical reaction mechanism. ${ }^{37}$ The relative increase in surface area of the treated Pd electrode $(R)$ was evaluated by the voltammetric charge ratio, $R=q_{\mathrm{rt}} / q_{\mathrm{rs}}$, where $q_{\mathrm{rt}}$ and $q_{\mathrm{rs}}$ stand for the apparent electroreduction voltammetric charge density of treated and smooth Pd, respectively. The value of $R$ was taken as an operational roughness factor of treated Pd specimens.

3.2. Voltammetric Electroreduction of the Pd Oxide Layer Produced by PRT. A linear potential scan run from $1.3 \mathrm{~V}$ to $0.15 \mathrm{~V}$ at $0.005 \mathrm{~V} / \mathrm{s}$ immediately after the PRT treatment for $\mathrm{E}_{1}=0 \mathrm{~V}, \mathrm{E}_{\mathrm{u}}=1.7 \mathrm{~V}, \mathrm{f}=1$ $\mathrm{kHz}, \tau_{\mathrm{u}} / \tau_{1}=9$, and $t_{\mathrm{prt}}=1 \mathrm{~min}$ (Figure $2 \mathrm{a}$ ) shows no cathodic current around $0.7 \mathrm{~V}$, as seen in Figure 1, but a large sharp and symmetric cathodic current peak $\left(C_{\text {ox }}\right)$ at ca. $0.4 \mathrm{~V}$, which corresponds to the electroreduction of the Pd oxide layer built up during the PRT treatment. Following peak $C_{\text {ox }}$ a small cathodic peak at ca. $0.25 \mathrm{~V}$ overlapping a continuous current increase can be observed. These current contributions are related to the hydrogen electrode reaction on Pd. The reverse potential scan exhibits the anodic hydrogen electrooxidation current hump together with a small anodic current peak at $0.25 \mathrm{~V}$. The conjugated pair of peaks at around $0.25 \mathrm{~V}$ has been unambiguosly assigned to $\mathrm{H}$ atom electrodesorption processes on $\mathrm{Pd}^{14,19,20,23}$ Subsequently, the cyclic voltammograms tend to reproduce the features described above for Figure 1, together with those current peaks related to the $\mathrm{H}$ atom electrode reactions.

Similar runs made for $t_{\mathrm{prt}}>3 \mathrm{~min}$ (Figure $2 \mathrm{~b}$ ) show that peak $C_{\text {ox }}$ partially overlaps a background cathodic current plateau which corresponds to the electroreduction of soluble Pd(II) species. ${ }^{35-37}$ These facts rule out the evaluation of the amount of Pd oxide accumulated by PRT for $t_{\mathrm{prt}}>3 \mathrm{~min}$ through the electroreduction charge resulting from peak $C_{\mathrm{ox}}$.

The cathodic charge involved in peak $C_{0 x}$ increases with $t_{\mathrm{prt}}$ at least in the range $0 \leq t_{\mathrm{prt}} \leq 3 \mathrm{~min}$, and reaches a limiting value for $t_{\mathrm{prt}}>20 \mathrm{~min}$. It should be noted that the Pd oxide layer built up for $t_{\mathrm{prt}}>3 \mathrm{~min}$ could not be completely electroreduced within a single potential scan at $0.005 \mathrm{~V} / \mathrm{s}$.

The electroreduction potential range moves negatively on increasing the Pd oxide layer charge. At a constant Pd oxide layer charge, the peak potential shifts linearly with $\log \mathrm{v}$, with the slope $-2.3 R T / F(-0.059 \mathrm{~V} / \mathrm{dec}$ ade, Figure $3 \mathrm{a})$. Furthermore, the height of current peak $C_{\text {ox }}$ increases linearly with $v$ (Figure 3b). These results are consistent with an electrochemical surface process with a Tafel slope equal to $-2.3(2 R T / F)(-0.118 \mathrm{~V} /$ decade $){ }^{34}$

These runs, as well as the majority of those described above, imply $q_{\mathrm{c}} / q_{\mathrm{a}} \cong 0.6$, where $q_{\mathrm{a}}$ and $q_{\mathrm{c}}$ are the anodic and cathodic charge density, respectively, resulting from the voltammograms. The fact that $q_{\mathrm{a}}>q_{\mathrm{c}}$ indicates that either the Pd oxide layer characteristics change during its own formation yielding Pd oxide species which are not electroreduced at $E_{1}$ or a localized electrodissolution of Pd as $\mathrm{Pd}(\mathrm{II})$-soluble species takes place during the anodic reaction so that the faradaic yield for Pd oxide layer electroformation is overestimated. In fact, rotating ring-

(35) Rand, D. A. J.; Woods, R. J. Electroanal. Chem. 1971, 31, 29.

(36) Cadle, S. H.; J. Electrochem. Soc. 1974, 121, 645.

(37) Bolzan, A. E.; Martins, M. E.; Arvia, A. J. J. Electroanal. Chem. 1984, $172,221$.
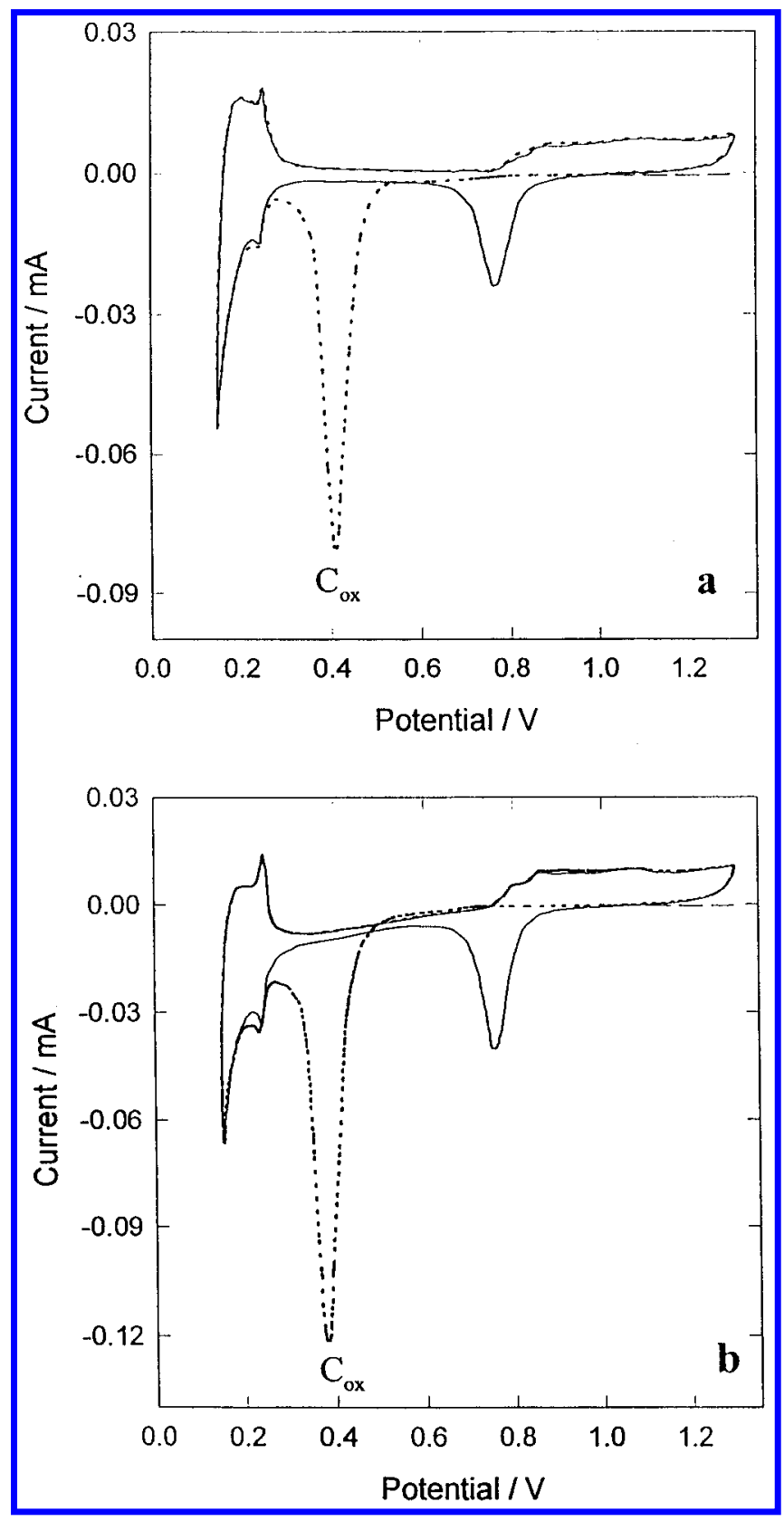

Figure 2. Voltammograms run at $0.005 \mathrm{~V} / \mathrm{s}$ in $1 \mathrm{M} \mathrm{H}_{2} \mathrm{SO}_{4}, 25$ ${ }^{\circ} \mathrm{C}$, showing the electroreduction peak $C_{\text {ox }}$ of the $\mathrm{Pd}$ oxide layer formed by PRT at $E_{1}=0 \mathrm{~V} ; E_{\mathrm{u}}=1.7 \mathrm{~V}, f=1 \mathrm{kHz} ; \tau_{\mathrm{u}} / \tau_{1}=9$. (a) $t_{\mathrm{prt}}=1 \mathrm{~min}$. (b) $t_{\mathrm{prt}}=8 \mathrm{~min}$. The dashed and the full trace correspond to the first and second voltammetric cycle, respectively.

disk electrode data have confirmed the formation of $\mathrm{Pd}(\mathrm{II})$ soluble species during an anodic potential scan of $\mathrm{Pd}$ in acids. ${ }^{36,37}$

3.3. Potentiostatic Electroreduction of the Pd oxide Layer Produced by PRT. The electroreduction current transients (Figure 4a) exhibit an initial current decay followed by a current maximum. The height and the time at which this maximum can be observed increase with $t_{\mathrm{prt}}$. The characteristics of Pd oxide layer electroreduction current transients resemble those of Au oxide and Pt oxide layers in acid already reported. ${ }^{15,38}$

The complex shape of the electroreduction current transients can reasonably be reproduced assuming that the formation of Pd from the oxide phase involves an

(38) Bolzan, A. E.; Castro Luna, A. M.; Visintin, A.; Salvarezza, R. C.; Arvia, A. J. Electrochim. Acta 1988, 33, 1743. 

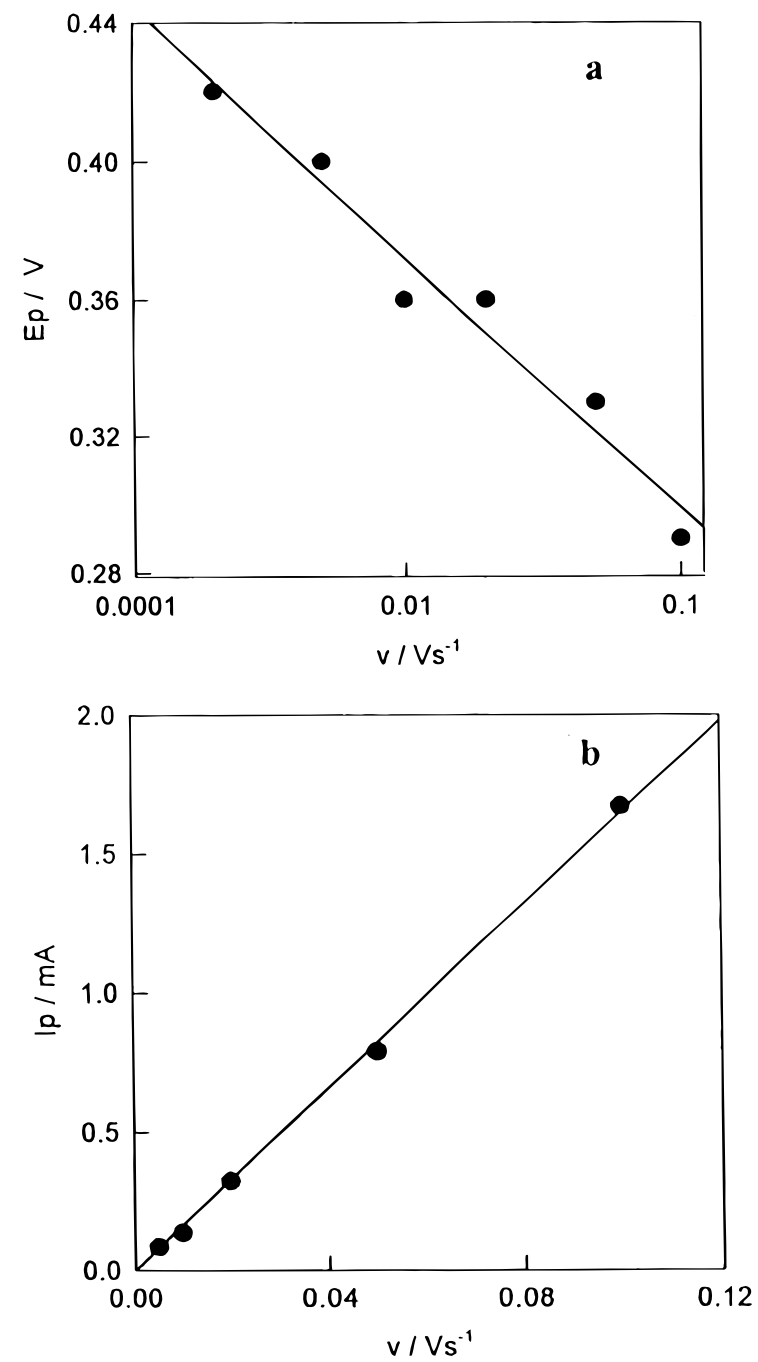

Figure 3. (a) Semilogarithmic plot for the potential of peak $\mathrm{C}_{0 \mathrm{x}}$ vs potential scan rate. (b) Current peak $\mathrm{C}_{\mathrm{ox}}$ height vs potential scan rate plot. Data taken from Pd oxide layers prepared as indicated in Figure 1.

instantaneous nucleation and 3D growth process. This is consistent with the appearance of a hysteresis loop in the electroreduction voltammetric scan (Figure 4b), which is typical of that type of process. ${ }^{38-40}$ Seemingly, the nucleation and growth process is limited by a surface electrochemical reaction, a fact which is consistent with the slope $-2.3(2 R T / F)(-0.118 \mathrm{~V} /$ decade $)$ referred to in section 3.2 .

Reliable charge data related to the Pd oxide layer resulting from the PRT treatment were obtained by integration of the electroreduction current transients run at $E=0.40 \mathrm{~V}$ (Figure $4 \mathrm{a}$ ), a potential at which the $\mathrm{Pd}$ oxide layer is no longer observed.

For $t_{\mathrm{prt}}<100 \mathrm{~s}$, the value of $q_{\mathrm{rp}}$, the potentiostatic electroreduction charge density, increases almost linearly with $t_{\text {prt }}$ (Figure 5), whereas for $t_{\text {prt }}>100$ s a slower increase in the charge density is observed. These results indicate that the formation of the $\mathrm{Pd}$ oxide layer involves either a gradual decrease in the active area for Pd electrooxidation or oxide formation is accompanied by its dissolution in the acidic media.

3.4. Influence of the PRT Parameters on $\mathbf{R}$. The influence of PRT parameters on $\mathrm{R}$ was systematically studied by changing $E_{1}, E_{\mathrm{u}}, f$, and the $\tau_{\mathrm{u}} / \tau_{1}$ ratio. These

(39) Fletcher, S.; Halliday, C. S.; Gates, D.; Westcott, M.; Lwin, T.; Nelson, G. J. Electroanal. Chem. 1983, 159, 267.

(40) Bolzan, A. E.; Arvia, A. J. J. Electroanal. Chem. 1992, 322, 247.

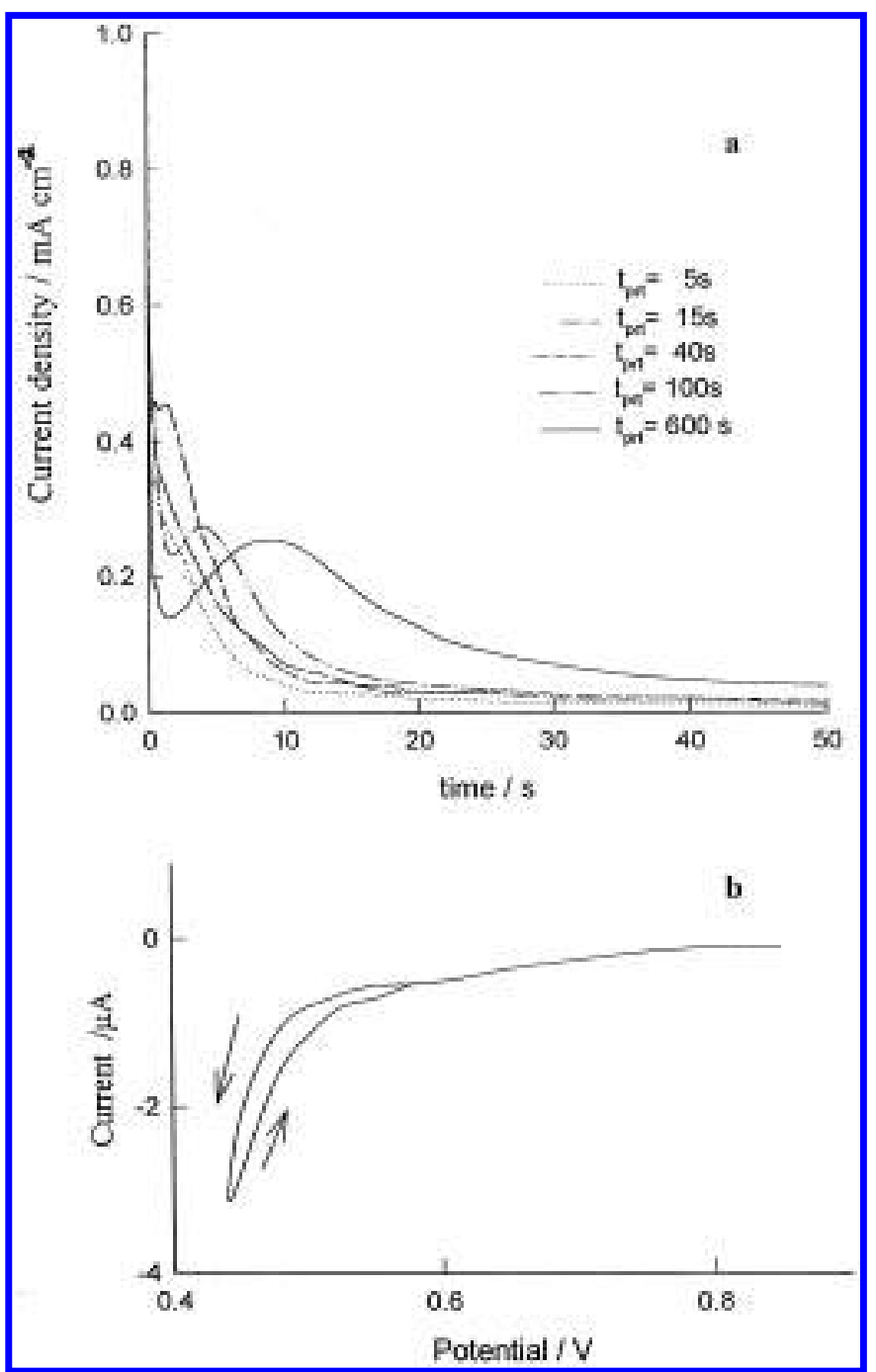

Figure 4. (a) Pd oxide layer electroreduction current transients at $\mathrm{E}=0.4 \mathrm{~V}$ in $1 \mathrm{M} \mathrm{H}_{2} \mathrm{SO}_{4}, 25^{\circ} \mathrm{C}$, for different $t_{\text {prt }}$. (b) First voltammogram run at $0.005 \mathrm{~V} / \mathrm{s}$ from 1.40 to $0.44 \mathrm{~V}$ related to the electroreduction of a Pd oxide layer for $t_{\mathrm{prt}}=3 \mathrm{~min}$. $E_{\mathrm{l}}=$ $0 \mathrm{~V} ; E_{\mathrm{u}}=1.7 \mathrm{~V}, f=1 \mathrm{kHz} ; \tau_{\mathrm{u}} / \tau_{1}=9$.

results allowed us to estimate the range of efficient conditions for producing Pd electrodes with a large value of $R$.

To establish the dependence of $R$ on $E_{\mathrm{u}}$ runs were made by setting $E_{\mathrm{l}}=0.15 \mathrm{~V}, f=1 \mathrm{kHz}, \tau_{\mathrm{u}} / \tau_{1}=9$, and $t_{\mathrm{prt}}=3$ min. These results (Figure 6) show that $R$ attains a maximum value for $E_{\mathrm{u}} \cong 1.7 \mathrm{~V}$. At higher positive potentials the oxygen evolution reaction favors the detachment of the Pd oxide layer.

Similarly, the influence of $\mathrm{E}_{1}$ on $\mathrm{R}$ was determined (Figure 7) by setting $\mathrm{E}_{\mathrm{u}}=1.7 \mathrm{~V}$. Large values of $R$ were obtained for $-0.1 \mathrm{~V} \leq E_{1} \leq 0.3 \mathrm{~V}$. It should be noted that after applying the PRT under this range of $E_{\mathrm{l}}$ for $E_{\mathrm{u}}=1.7$ $\mathrm{V}, f=1 \mathrm{kHz}, \tau_{\mathrm{u}} / \tau_{1}=9$, and $t_{\mathrm{prt}}=3 \mathrm{~min}$, no current contribution due to $\mathrm{Pd}-\mathrm{H}$ alloy formation could be voltammetrically detected.

The dependence of $R$ on $f$ determined by setting $E_{\mathrm{u}}=$ $1.7 \mathrm{~V}, E_{\mathrm{l}}=0 \mathrm{~V}, \tau_{1} / \tau_{\mathrm{u}}=1$, and $t_{\mathrm{prt}}=3 \mathrm{~min}$ showed a maximum value of $\mathrm{R}$ for $0.5 \mathrm{kHz} \leq f \leq 1.0 \mathrm{kHz}$ (Figure 8). For this set of conditions only, the $q_{\mathrm{a}} / q_{\mathrm{c}}$ ratio was close to unity. Otherwise, the $\mathrm{PdO}$ layer electroreduction yield was about $60 \%$.

Finally, the dependence of $R$ on $\tau_{\mathrm{u}} / \tau_{1}$ at a constant $\mathrm{f}$, by setting $E_{\mathrm{u}}=1.7 \mathrm{~V}$ and $E_{\mathrm{l}}=0 \mathrm{~V}$, indicates the existence of a maximum value of $R$ at $\tau_{\mathrm{u}} / \tau_{1}=9$ (Figure 9 ). This plot shows a relatively small range of $\tau_{\mathrm{u}} / \tau_{1}$ related to a remarkable increase in $R$. 


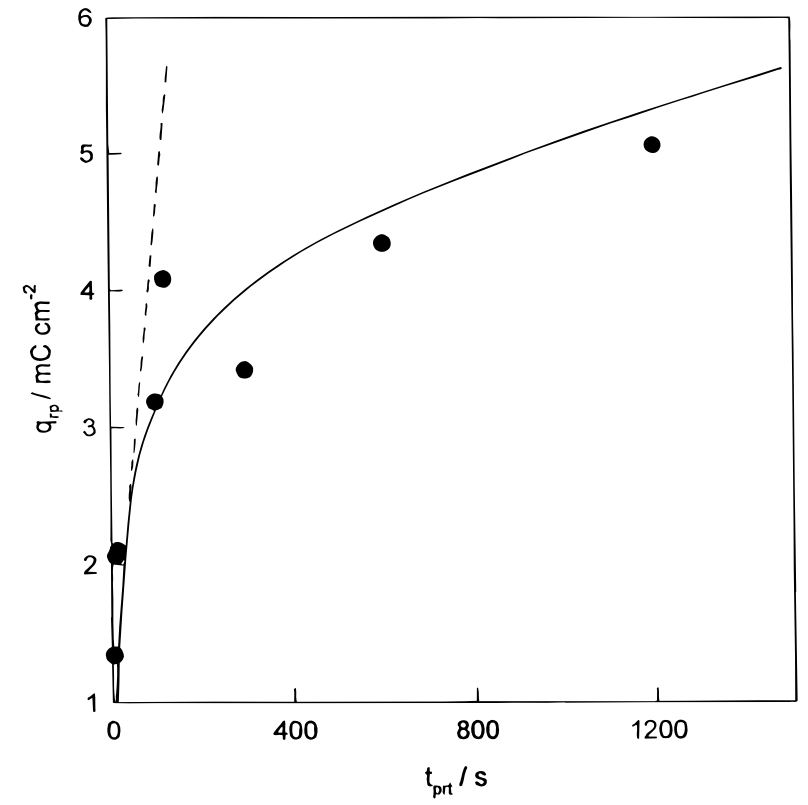

Figure 5. Dependence of $q_{\mathrm{rp}}$ on $t_{\mathrm{prt}} . E_{\mathrm{l}}=0 \mathrm{~V} ; E_{\mathrm{u}}=1.7 \mathrm{~V}, f=$ $1 \mathrm{kHz} ; \tau_{\mathrm{u}} / \tau_{1}=9.1 \mathrm{M} \mathrm{H}_{2} \mathrm{SO}_{4}$ at $25{ }^{\circ} \mathrm{C}$.

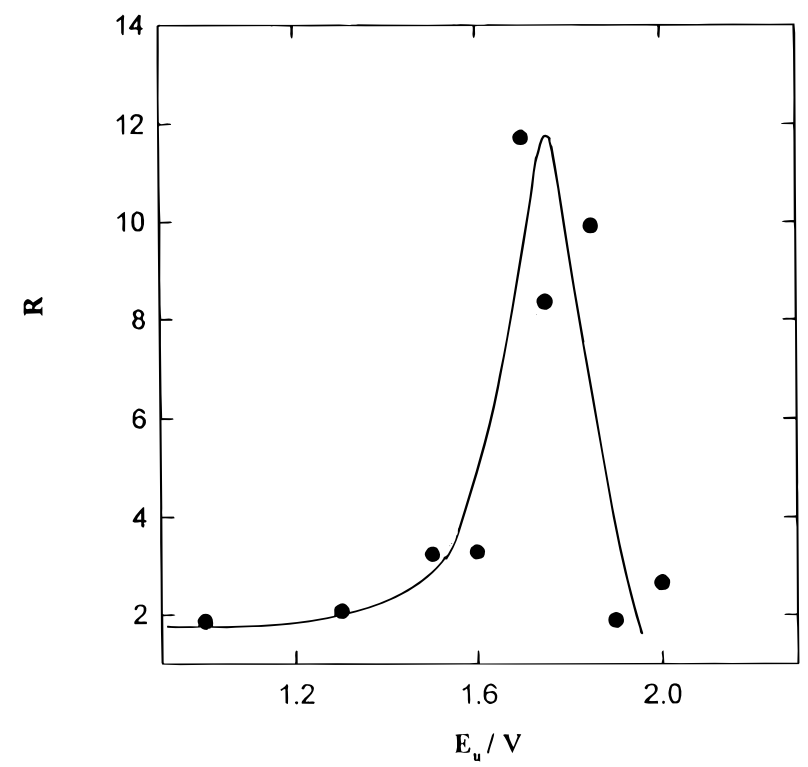

Figure 6. Dependence of $R$ on $E_{\mathrm{u}}$ for treated Pd. $E_{\mathrm{l}}=0.15 \mathrm{~V}$; $f=1 \mathrm{kHz} ; \tau_{\mathrm{u}} / \tau_{1}=9, t_{\mathrm{prt}}=3 \mathrm{~min} .1 \mathrm{M} \mathrm{H}_{2} \mathrm{SO}_{4}$ at $25{ }^{\circ} \mathrm{C}$.

3.5. Comparative Voltammetric Response of $\mathrm{Hy}$ drogen Electrode Reactions on Smooth and Treated Pd. A conventional single-sweep voltammogram of a smooth $\mathrm{Pd}$ electrode in aqueous $1 \mathrm{M} \mathrm{H}_{2} \mathrm{SO}_{4}$ run between 0.15 and $0.60 \mathrm{~V}$ at $0.1 \mathrm{~V} / \mathrm{s}$ (Figure 10 ) shows a continuous cathodic current increase as the potential is shifted from $0.60 \mathrm{~V}$ downwards and a broad anodic peak in the reverse potential scan from $0.15 \mathrm{~V}$ upward. This voltammogram has been widely interpreted in terms of hydrogen electrode reactions comprising the simultaneous contribution of $\mathrm{H}$-atom electroadsorption and hydrogen electroabsorption processes. ${ }^{14,19-25,30,41}$ It should be noted that the reversible faradaic processes at ca. $0.24 \mathrm{~V}$ (vs RHE) for Pd in acid solution have been recently attributed to a premonolayer oxidation effect, ${ }^{9}$ an interpretation that was not considered in our work. In fact, as discussed elsewhere,${ }^{10}$ this is a controversial approach for which an unquestionable direct evidence of the species involved in incipient hydrous metal oxide layers is lacking.

(41) Lewis, F. A. The Palladium-Hydrogen System; Academic Press: London, 1967.

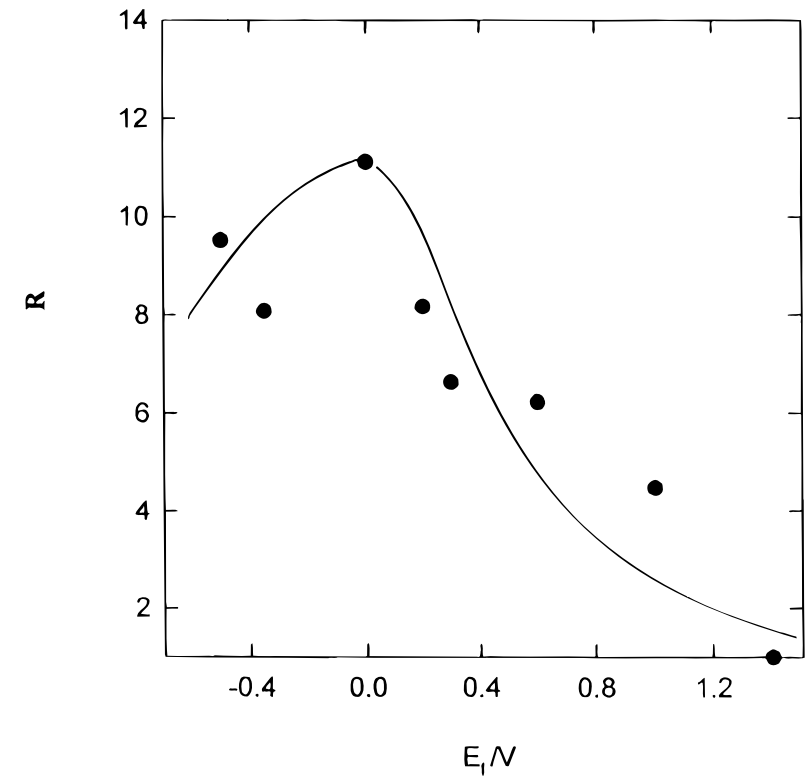

Figure 7. Dependence of $R$ on $E_{\mathrm{l}}$ for treated Pd. $E_{\mathrm{u}}=1.7 \mathrm{~V}$, $f=1 \mathrm{kHz} ; \tau_{\mathrm{u}} / \tau_{1}=9, t_{\mathrm{prt}}=3 \mathrm{~min} .1 \mathrm{M} \mathrm{H}_{2} \mathrm{SO}_{4}$ at $25{ }^{\circ} \mathrm{C}$.

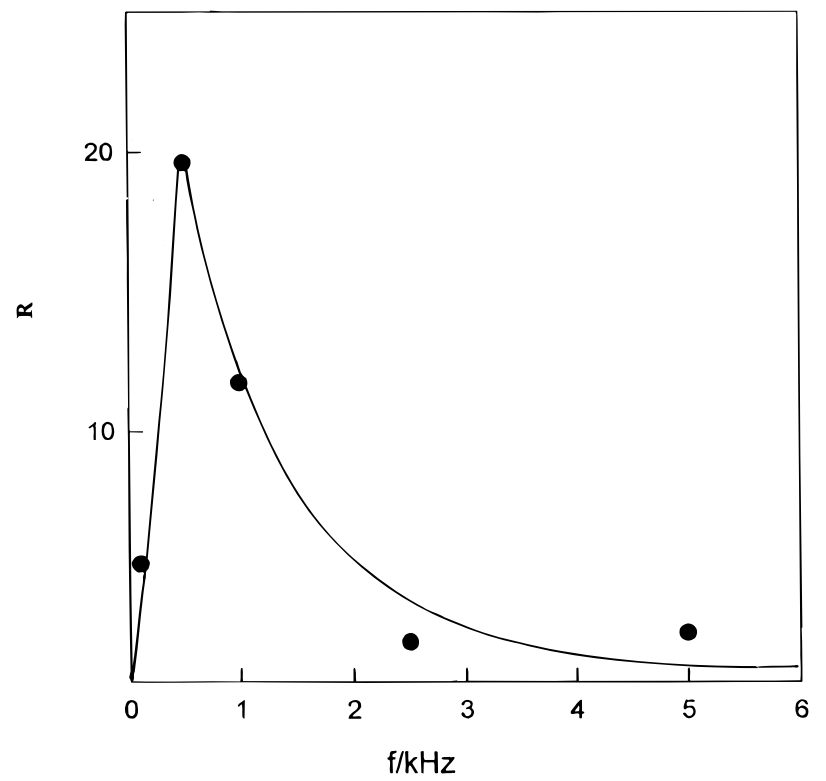

Figure 8. Dependence of $R$ on $f$ for treated Pd. $E_{\mathrm{l}}=0 \mathrm{~V}, E_{\mathrm{u}}$ $=1.7 \mathrm{~V}, \tau_{\mathrm{u}} / \tau_{1}=9, t_{\mathrm{prt}}=3 \min .1 \mathrm{M} \mathrm{H}_{2} \mathrm{SO}_{4}$ at $25^{\circ} \mathrm{C}$.

A similar voltammogram run with a treated $\mathrm{Pd}$ electrode (Figure 10) shows a remarkable difference as compared to that recorded for smooth $\mathrm{Pd}$. It consists of a pair of sharp, reversible conjugated peaks at $0.23-0.25 \mathrm{~V}$ overlapping the voltammogram described above for smooth $\mathrm{Pd}$. The deconvolution of the voltammogram revealed that approximately one-half of the overall charge is related to the conjugated pair of peaks associated with the $\mathrm{H}$-atom electroadsorption/electrodesorption processes on $\mathrm{Pd}$ in the acid solution, the remaining faradaic charge corresponding to hydrogen electroabsorption.

3.6. TMTPS Voltammetric Data. The TMTPS voltammogram of a fresh Pd electrode run between 0.05 $\mathrm{V}$ and $1.5 \mathrm{~V}$ at $0.3 \mathrm{~V} / \mathrm{s}$ and at $f=2 \mathrm{kHz}$ and $A=0.04 \mathrm{~V}$ shows during the positive-going potential scan (Figure 11a) two conjugated pairs of current peaks at $0.3 \mathrm{~V}$ and $0.8 \mathrm{~V}$, the former being assigned to the fast electroadsorption of $\mathrm{H}$ atoms on $\mathrm{Pd}$, whereas the latter corresponds to the fast electroformation and electroreduction of the $\mathrm{PdOH}$ species considered as a precursor of $\mathrm{Pd}$ oxide formation. ${ }^{29}$ 


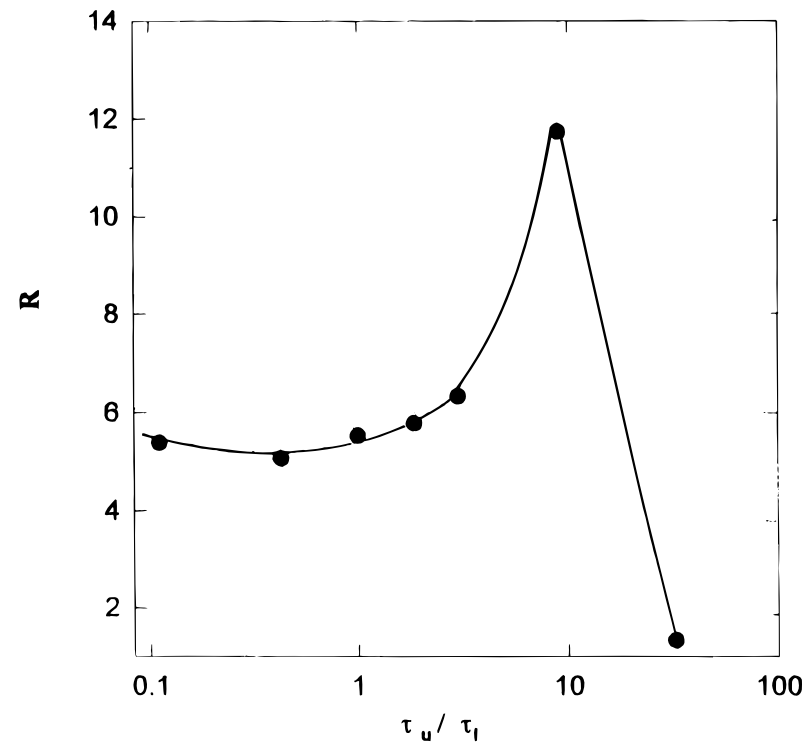

Figure 9. Dependence of $R$ on $\log \left(\tau_{\mathrm{u}} / \tau_{1}\right)$ for treated Pd. $E_{1}=$ $0 \mathrm{~V}, E_{\mathrm{u}}=1.7 \mathrm{~V}, f=1 \mathrm{kHz} ; t_{\mathrm{prt}}=3 \min .1 \mathrm{M} \mathrm{H}_{2} \mathrm{SO}_{4}$ at $25^{\circ} \mathrm{C}$.

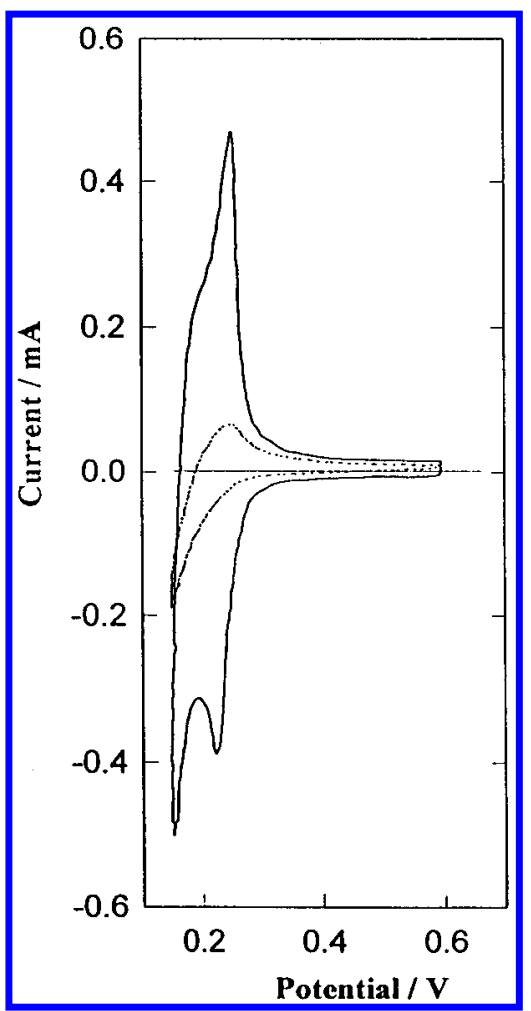

Figure 10. Voltammograms run at $0.1 \mathrm{~V} / \mathrm{s}$ between 0.15 and $0.60 \mathrm{~V}$ for smooth Pd (dotted trace); treated Pd (full trace): $E_{\mathrm{l}}$ $=0 \mathrm{~V} ; E_{\mathrm{u}}=1.7 \mathrm{~V}, f=1 \mathrm{kHz} ; \tau_{\mathrm{u}} / \tau_{1}=9, t_{\mathrm{prt}}=3 \mathrm{~min}$ followed by potentiostatic electroreduction at $0.4 \mathrm{~V}$ for $30 \mathrm{~min}$. $1 \mathrm{M} \mathrm{H}_{2} \mathrm{SO}_{4}$, $25{ }^{\circ} \mathrm{C}$.

The characteristics of the sharp pair of conjugated peaks related to the electroadsorption of $\mathrm{H}$ atoms are independent of the potential scanning direction (Figure 11a,b). This is an indication of the reversibility of $\mathrm{H}$-atom electroadsorption on Pd in acidic solution. The apparent charge density involved in those reversible processes, estimated from the corresponding current peaks, is about the same. A similar reversible behavior is observed for the $\mathrm{OH}$ electroadsorption/electrodesorption at $0.8 \mathrm{~V}$.

On the other hand, the TMTPS voltammogram run in the negative potential direction (Figure 11b) differs from that previously run in the positive potential direction, as only a minor contribution to the $\mathrm{OH}$ electroadsorption/

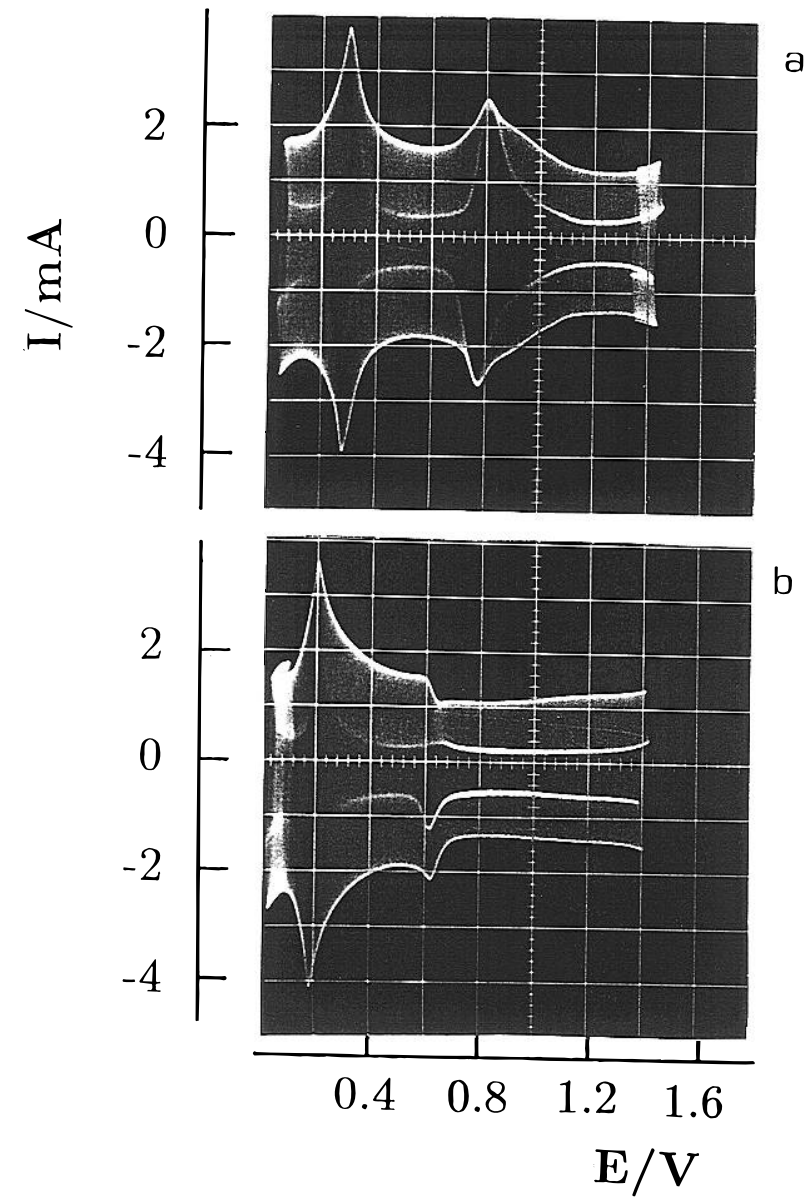

Figure 11. TMTPS voltammograms of smooth $\mathrm{Pd}$ in aqueous $1 \mathrm{M} \mathrm{H}_{2} \mathrm{SO}_{4}$, run at $v=0.3 \mathrm{~V} / \mathrm{s}, A=0.04 \mathrm{~V}, f=2 \mathrm{kHz}, 25{ }^{\circ} \mathrm{C}$. (a) Positive-going potential scan. (b) Negative-going potential scan.

electrodesorption due to the aging of the $\mathrm{Pd}$ oxide layer produced during the electrooxidation scan can be seen. In this case, the small electroreduction current peak observed at ca. $0.63 \mathrm{~V}$ coincides with that for the untreated $\mathrm{Pd}$ electrode already described in the literature. ${ }^{29}$

In addition, the fact that the reversible behavior of both $\mathrm{H}$ and $\mathrm{OH}$ adsorbed species appears for $f$ in the kilohertz range indicates that the half-life time of these species on $\mathrm{Pd}$ at the corresponding electroadsorption potential in the acidic solution is of the order of $1 \mathrm{~ms}$, as earlier reported. ${ }^{29}$ This figure agrees with data on TMTPS of $\mathrm{Pt}^{28}$ and $\mathrm{Au}^{42}$ in acidic solutions.

3.7. SFM Characterization of Pd Electrode Surfaces. Relevant information about the topography of the $\mathrm{Pd}$ layer built up by electroreducing the Pd oxide can be obtained using partially masked Pd electrodes. A rectangular $0.5 \times 1.0 \mathrm{~cm}^{2} \mathrm{Pd}$ electrode was partially covered by Teflon leaving a $0.2 \mathrm{~cm}^{2}$ uncovered area at its central domain. Then, the Pd oxide layer was accumulated on the electrode by applying PRT operating conditions within the high-efficiency range for $t_{\mathrm{prt}}=3 \mathrm{~min}$. Subsequently, the Pd oxide layer was electroreduced by stepping the potential from $E=1.7$ to $0.4 \mathrm{~V}$. As the $\mathrm{Pd}$ oxide layer electroreduction was completed, the electrode was removed from the cell and dried in air, and SFM images were taken. This procedure allowed us to compare on the same specimen the topography of smooth Pd (masked region) with the topography of the treated Pd (unmasked region).

(42) Ferro, C. M.; Calandra, A. J.; Arvia, A. J. J. Electroanal. Chem. 1975, 59, 239. 
SFM images of smooth Pd and treated Pd with $R=8$ revealed the same type of large well-defined grains.

Conversely, substantial differences between 3D SFM images $\left(2 \times 2 \mu \mathrm{m}^{2}\right)$ of Pd specimens can be observed (Figure 12). The topography of smooth Pd consists of a flat surface with steps and terraces with small bumps (Figure 12a), whereas that of treated $\mathrm{Pd}$ exhibits an irregular surface made of small columnar elements $30 \mathrm{~nm}$ in average size (Figure 12b).

The cross-section analysis (Figure 13) of smooth Pd (lefthand side) and treated Pd topography surface (right-hand side) shows that height fluctuations for the treated specimen are 6 times greater than that for smooth $\mathrm{Pd}$, and the base plane of treated Pd is shifted inward as compared to smooth Pd.

These results confirm that the formation of the Pd oxide layer by PRT involves the dissolution of the Pd substrate and the inward displacement of the reaction front, leading to an oxide layer with a greater volume than that of the dissolved metal layer, as expected from the $\mathrm{Pd}$ oxide/Pd density ratio. In addition, the columnar-like topography of treated Pd suggests that its formation can be described as a Pd oxide-to-Pd phase change occurring at a constant volume which is similar to the volume occupied by the $\mathrm{Pd}$ oxide layer. Therefore, the mechanism of Pd oxide layer electroreduction appears to be the same as that previously reported for the electroreduction of $\mathrm{Au}^{15}$ and $\mathrm{Pt}$ oxide layers. ${ }^{38,43}$

The SFM surface characterization of both Pd specimens indicates that the surface structure on the micrometer scale remains almost the same (Figure 14), as in the case of grain boundaries which are preferred routes for hydrogen absorption into $\mathrm{Pd}^{44}$ Hence, as far as this process is concerned, no marked changes should be expected for smooth and treated Pd, in agreement with electrochemical data. Conversely, the Pd oxide formation/ electroreduction procedure changes markedly the surface structure on the nanometer scale leading to an irregular columnar-like structure. This implies a substantial increase in the real surface area of treated Pd electrodes, as revealed by electrochemical surface processes (Figure $1)$.

3.8. Fractal Characterization. The fractal characterization of the treated Pd surface is extremely valuable to understand the behavior of $\mathrm{H}$-atom adsorption and hydrogen absorption on this type of electrode. The fractal nature of the treated Pd surface was investigated by using the perimeter-area method applied to the SFM images. ${ }^{45}$ This method is based on the fact that the intersection of a plane with a self-affine or self-similar fractal generates self-similar "lakes" or "islands". For each "lake" or "island" the following proportionality between $P$, the perimeter of either "a lake" or "an island", and A, the corresponding area, has been established: ${ }^{46}$

$$
P \propto A^{D_{1} / 2}
$$

where $D_{l}$ is the fractal dimension of the "lake" or "island" perimeter. Furthermore, $D_{l}$ is related to $D_{\mathrm{s}}$, the fractal dimension of the surface, by

$$
D_{\mathrm{s}}=D_{1}+1
$$

Therefore, considering eqs 1 and 2, from an adequate $\log P$ vs $\log A$ plot the value of $D_{\mathrm{s}}$ can be obtained. Briefly,

(43) Arvia, A. J.; Salvarezza, R. C.; Triaca, W. E. Electrochim. Acta 1989, $34,1057$.

(44) Subramanyan, P. K. In Comprehensive Treatise of Electrochemistry, Bockris, J. O'M., Conway, B. E., Yeager, E., White, R., Eds.; Plenum Press: New York, 1981; Vol. 4, Chapter 8, p 411.
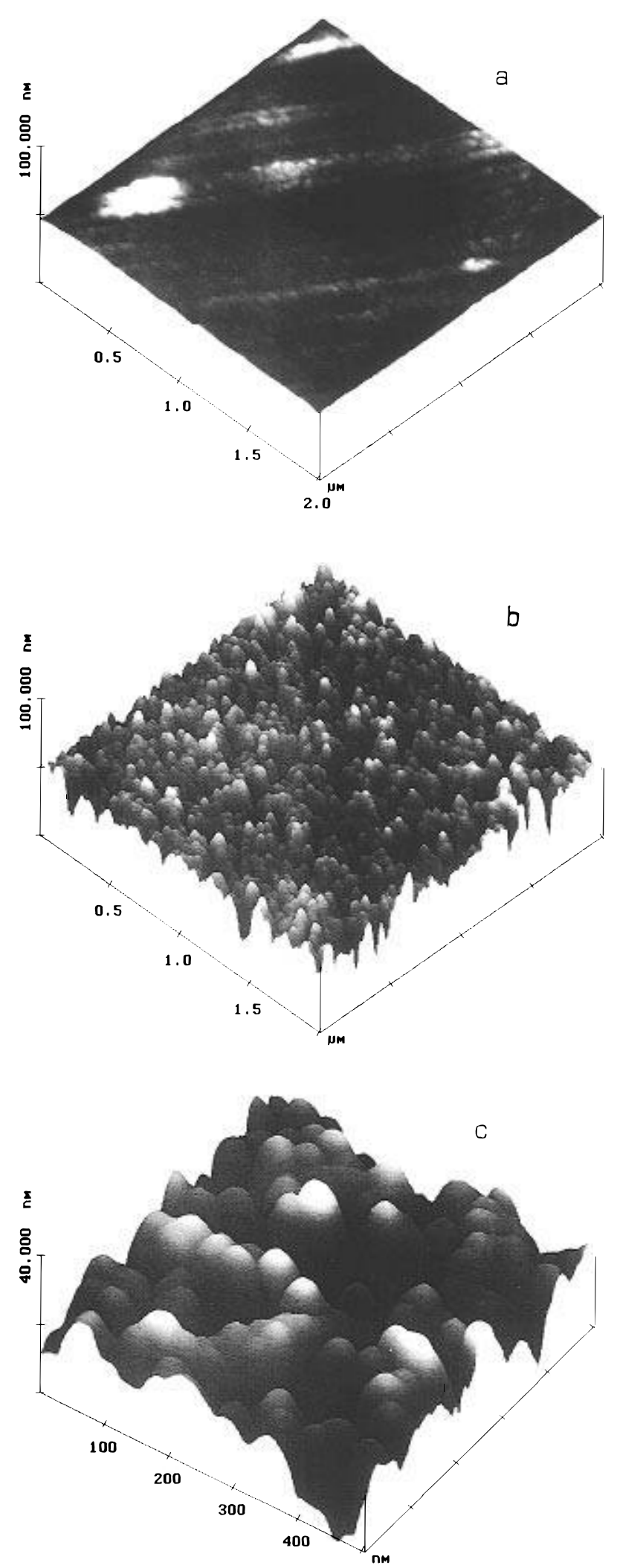

Figure 12. SFM topographic images $\left(2 \times 2 \mu \mathrm{m}^{2}\right)$. (a) Annealed Pd. (b) Annealed Pd after Pd oxide layer electroformation under the following PRT conditions, $E_{\mathrm{l}}=0 \mathrm{~V} ; E_{\mathrm{u}}=1.7 \mathrm{~V}, f=1 \mathrm{kHz}$; $\tau_{\mathrm{u}} / \tau_{1}=9, t_{\mathrm{prt}}=3 \mathrm{~min}$, and subsequent electroreduction by a potential step from 1.7 to $0.4 \mathrm{~V}$ followed by a potential holding at $0.4 \mathrm{~V}$ for $30 \mathrm{~min}$. (c) High resolution image $\left(500 \times 500 \mathrm{~nm}^{2}\right)$ over a restricted Pd surface domain.

(45) Gómez Rodríguez, J. M.; Baró, A. M.; Vázquez, L.; Salvarezza, R. C.; Vara, J. M.; Arvia, A. J. J. Phys. Chem. 1992, 96, 347.

(46) Meakin, P. In The Fractal Approach to Heterogeneous Chemistry, Avnir, D., Ed.; John Wiley and Sons Inc.: New York, 1989; p 131. 

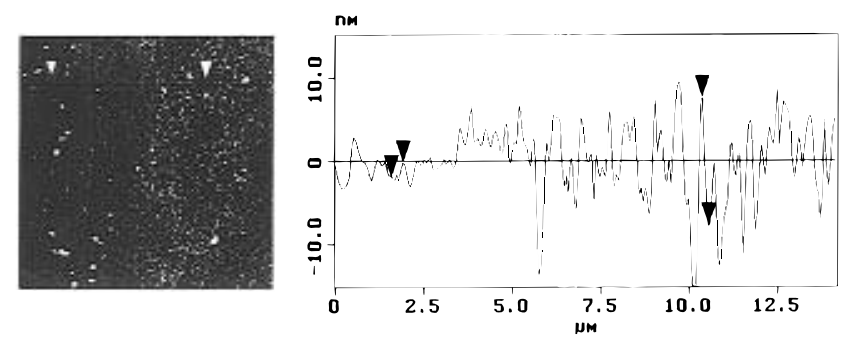

Figure 13. Cross section analysis of an SFM image of a Pd substrate consisting of a masked (left-hand side) and unmasked (right-hand side) region. The unmasked region was subjected to the electrochemical treatment indicated for Figure $12 \mathrm{~b}$.

the application of the perimeter-area method to SFM imaging involves the following steps: (i) the simulation of the "water-filling" of "lakes" of the irregular surface up to a given level; (ii) the measurement of both $P$ and $A$ for those self-similar "lakes" or "islands" generated by the "water-filling" procedure, using a yardstick of size $\epsilon$, which is equal to the size of the pixel on the grid $(\epsilon=$ number of pixels in the SFM image/image size); (iii) the determination of $D_{l}$ from the slope of the $\log P$ vs $\log A$ plot; (iv) the evaluation of $D_{\mathrm{s}}$ from eq 2 . As already reported, ${ }^{47}$ to minimize errors in the evaluation of $D_{\mathrm{s}}$ only "lakes" or "islands" larger than $30 \epsilon$ should be considered for the application of the perimeter-area procedure. It should be noted that this procedure can be applied only to real 3D images as those solely provided by new nanoscopies.

Accordingly, the fractal characterization of treated Pd from SFM imaging data (Figure 15) yields $D_{l}=1.57 \pm$ 0.07 and $D_{\mathrm{s}}=2.57 \pm 0.07$. Thus, the treated Pd surface is an irregular fractal surface. The value $D_{\mathrm{s}}=2.57 \pm 0.07$ means that the object surface tends to fill the entire volume of the object, as has been previously observed for Pt and $\mathrm{Au}$ surfaces produced by the same electrochemical techniques. ${ }^{48,49}$

\section{Discussion}

4.1. Anodic Reactions Involved in the Voltammetric Sweep between 0.7 and $1.7 \mathrm{~V}$. As concluded from TMTPS voltammetry data, the electrooxidation of Pd begins at $0.7 \mathrm{~V}$ with the formation of a $\mathrm{Pd}(\mathrm{OH})$ surface species, according to a reversible reaction such as

$$
[\mathrm{Pd}]_{X}+\mathrm{H}_{2} \mathrm{O}=[\mathrm{Pd}]_{X}(\mathrm{OH})+\mathrm{H}^{+}+\mathrm{e}^{-}
$$

where $[\mathrm{Pd}]_{X}$ stands for Pd surface atoms and the parentheses indicate an adsorbed species. This type of reaction has been observed for a number of metals in aqueous acid environments ${ }^{43}$ and produces a surface coverage up to 1 ML. ${ }^{29}$ This adsorbate can be considered as the precursor of both the formation of $\mathrm{Pd}(\mathrm{II})$-soluble species and the growth of a Pd oxide layer, which occurs when the potential scan exceeds $0.7 \mathrm{~V}$. These complex processes can be formally expressed as

$$
[\mathrm{Pd}]_{X}(\mathrm{OH})=\mathrm{Pd}^{2+}+\mathrm{OH}^{-}+\mathrm{e}^{-}
$$

and

$$
\begin{gathered}
{[\mathrm{Pd}]_{X}(\mathrm{OH})=[\mathrm{Pd}]_{X}(\mathrm{O})+\mathrm{H}^{+}+\mathrm{e}^{-}} \\
{[\mathrm{Pd}]_{X}(\mathrm{O})=[\mathrm{Pd}]_{X-1}[\mathrm{PdO}]}
\end{gathered}
$$

Reaction 4 is assisted by the relatively high solubility of $\mathrm{PdSO}_{4} \cdot{ }^{50}$ Reaction 5 a corresponds to the formation of an O-containing surface layer, and reaction $5 \mathrm{~b}$ represents the appearance of an aged $\mathrm{PdO}$ phase presumably approaching the structure of bulk PdO. Further growth of the Pd(II) oxide layer can be represented by

$$
[\mathrm{Pd}]_{X^{-1}}[\mathrm{PdO}]+\mathrm{H}_{2} \mathrm{O}=[\mathrm{Pd}]_{X^{-}-}[\mathrm{PdO}]_{2}+2 \mathrm{H}^{+}+2 \mathrm{e}^{-}
$$

and so forth leading to multilayer formation. Reactions 4 to $5 \mathrm{c}$ also produce an inhomogeneously distributed $\mathrm{Pd}$ oxide layer, and a localized attack of $\mathrm{Pd}$ as has been observed by scanning microscopies. ${ }^{14}$

It is worth mentioning that our experimental data provide no evidence about the formation of appreciable amounts of Pd species with an oxidation level higher than 2. Pd oxidation levels higher than 2 have been reported under different conditions. ${ }^{6,8,51-54}$

4.2. Voltammetric Electroreduction of the Pd(II) Oxide Layer and Soluble Pd(II) Species. The voltammetric electroreduction data of the Pd oxide layer produced by PRT for $E_{\mathrm{u}} \leq 1.7 \mathrm{~V}$ (Figure 2) differ from those corresponding to a Pd(II) oxide monolayer produced in the range 0.8 to $1.4 \mathrm{~V} .^{14,31,55}$ Otherwise, the electroreduction of soluble $\mathrm{Pd}(\mathrm{II})$ is related to the limiting current plateau exhibited by the voltammogram for $E<0.6 \mathrm{~V} .{ }^{37}$ The simultaneous occurrence of both reactions in the acidic solution agrees with the thermodynamic predictions for reactions 4 and $5 \mathrm{a}-\mathrm{c},{ }^{56}$ taking into account that the concentration of soluble $\mathrm{Pd}$ (II) reached during voltammetric cycling is of the order of $10^{-7} \mathrm{M} .{ }^{14}$

Let us consider the relative contribution of both the $\mathrm{Pd}$ oxide layer and soluble $\mathrm{Pd}(\mathrm{II})$ species electroreduction yielding Pd. For this purpose it should be noted that under PRT conditions for $f=1 \mathrm{kHz}, \tau_{\mathrm{u}}=9 \tau_{\mathrm{l}}$, and $0.3 \mathrm{~V}<E_{\mathrm{l}}<$ $0.5 \mathrm{~V}$, the value of $L$, the average diffusion distance for soluble $\operatorname{Pd}(\mathrm{II})$ species can be estimated at $\tau_{\mathrm{u}}$ and $\tau_{1}$ considering that $L \cong(D \tau)^{1 / 2}$, where $D$ is the diffusion coefficient of soluble $\operatorname{Pd}(\mathrm{II})$ species and $\tau$ is either $\tau_{\mathrm{u}}$ or $\tau_{1}$. Thus, taking $D=10^{-5} \mathrm{~cm}^{2} / \mathrm{s}$ and $\tau_{\mathrm{u}}=2 \times 10^{-3} \mathrm{~s}$ results in $L \cong 10^{-4} \mathrm{~cm}$, whereas for $\tau_{1} \cong 10^{-4} \mathrm{~s}, L \cong 10^{-5} \mathrm{~cm}$. Therefore, under the PRT conditions above mentioned, the contribution of the diffusion-limited electrodeposition of Pd(II) species becomes, in principle, less significant than the electroreduction of the $\mathrm{Pd}(\mathrm{II})$ oxide layer itself in $\mathrm{Pd}$ phase formation.

In agreement with previously reported data, ${ }^{2,6,8}$ the voltammetric electroreduction of Pd oxide layers involves only about $60 \%$ of the amount produced in the positivegoing potential scan. This rather low electroreduction yield has been explained by the formation of a passive oxide layer at $1.6 \mathrm{~V}$ accompanied by the absorption of oxygen into the bulk of $\mathrm{Pd}^{33}$ It is worth mentioning that hydrous Pd oxide layers produced by a symmetric trian-

(47) Vázquez, L.; Vara, J. M.; Herrasti, P.; Ocón, P.; Salvarezza, R. C.; Arvia, A. J. Chaos, Solitons and Fractals 1995, 6, 569.

(48) Arvia, A. J.; Salvarezza, R. C. Electrochim. Acta 1994, 39, 1481

(49) Vázquez, L.; Salvarezza, R. C.; Ocón, P.; Herrasti, P.; Vara, J. M.; Arvia, A. J. Phys. Rev. E 1994, 49, 1507.

(50) Handbook of Chemistry and Physics, 57 th ed.; Weast, R. C., Ed.; CRC Press: Cleveland, 1977; p B138.

(51) Kim, K. S.; Gossmann, A. F.; Winograd, N. Anal. Chem. 1974 $46,197$.

(52) Jeong, M.-C.; Pyun, Ch. H.; Yeo, I.-H. J. Electrochem. Soc. 1993, $140,1986$.

(53) Tseung, A. C. S.; Jasen, S. Electrochim. Acta 1977, 22, 31

(54) Chausse, V.; Regull, P.; Victori, L. J. Electroanal. Chem. 1987, 238, 115 .

(55) Bolzan, A. E.; Martins, M. E.; Arvia, A. J. J. Electroanal. Chem 1983, 157, 339

(56) Colom, F. In Standard Potentials in Aqueous Solution; Bard, A. J., Parsons, R., Jordan J., Eds.; M. Dekker: New York, 1985; Chapter 12 , p 339. 
a
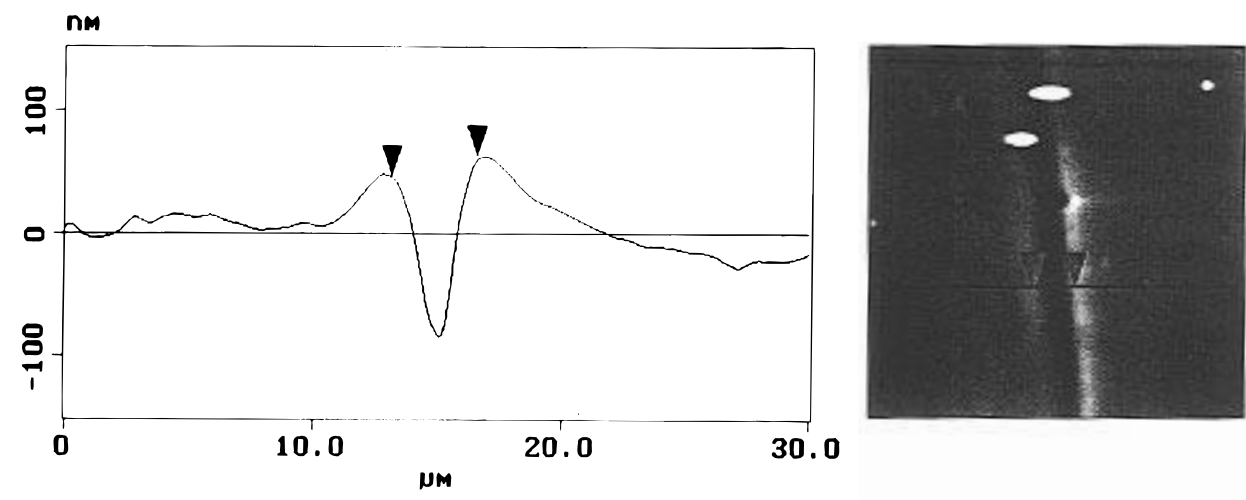

b
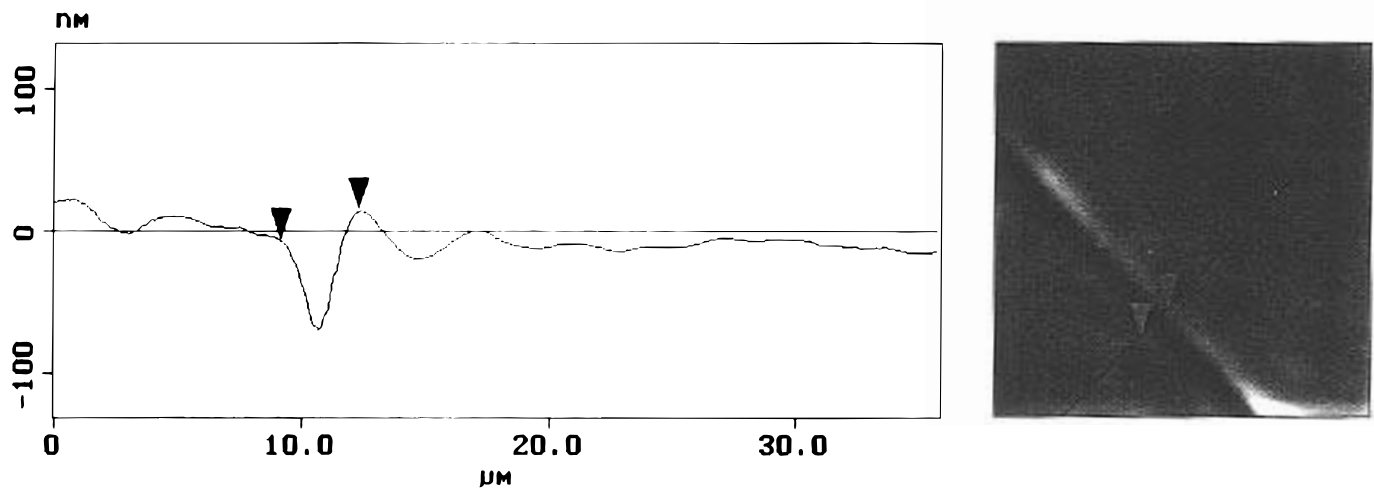

$1 \mathrm{M}$

Figure 14. Cross section analysis of SFM images covering a grain boundary. (a) Untreated Pd; (b) treated Pd electrode.

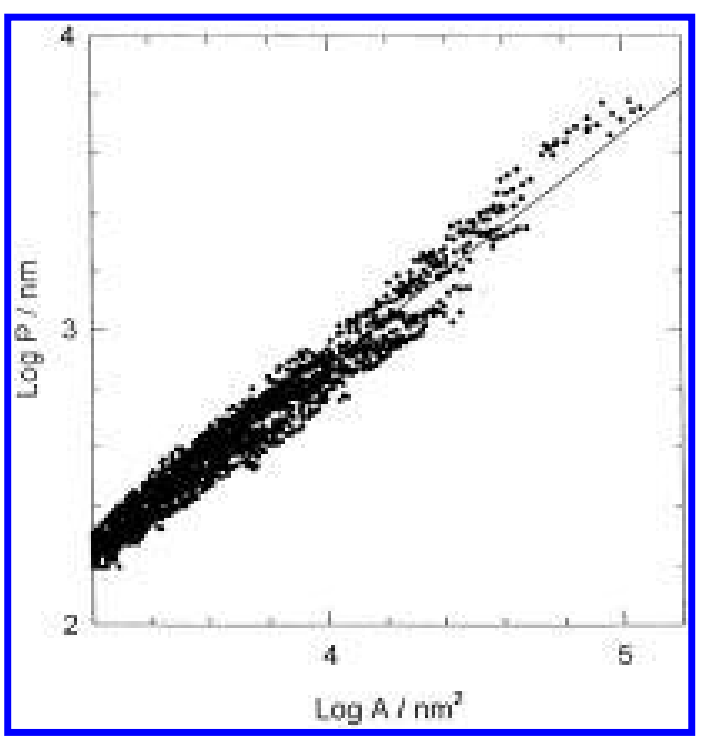

Figure 15. $\log P$ vs $\log A$ plot resulting from the fractal analysis of SFM images of treated Pd using the perimeter area method. The slope of the straight line is 0.785 .

gular potential scan by setting $E_{\mathrm{u}}=2.4 \mathrm{~V}, E_{\mathrm{l}}=0.48 \mathrm{~V}$, $V=0.5 \mathrm{~V} / \mathrm{s}$, and $t=1 \mathrm{~min}^{2,6}$ behave electrochemically differently from the Pd oxide layer referred to in this work, presumably because of the substantially different values of $\tau_{\mathrm{u}}$ and $\tau_{1}$ and switching potentials used.

According to our work, the complete electroreduction of the Pd oxide layer produced by PRT leads to a Pd overlayer with a columnar-like surface topography (Figure 12b,c). The mechanism involved in this process appears to be the same to that proposed earlier for Au and Pt oxide layers ${ }^{15,43}$ accumulated by PRT, at least for $t_{\mathrm{prt}}<100 \mathrm{~s}$, i.e., in the growth range where the amount (average thickness) of Pd oxide layer increases linearly with $t_{\mathrm{prt}}$. For $t_{\mathrm{prt}}>100$ $\mathrm{s}$, this linear relationship is no longer observed as a limiting $\mathrm{Pd}$ oxide layer charge is produced.
4.3. H-Atom Electroadsorption on Treated Pd Electrodes. The voltammogram of treated Pd electrodes in acidic solution shows a considerable enhancement of the $\mathrm{H}$-atom electroadsorption reactions (Figure 10) as has been shown for Pd electrodes resulting from the PRT treatment between 0.33 and $1.4 \mathrm{~V}$ and with $f$ ranging from 0.5 to $6.25 \mathrm{kHz},{ }^{14}$ as well as for palladised $\mathrm{Pt}$ electrodes. ${ }^{23}$ These results have been widely confirmed using different Pd-covered substrates. ${ }^{19,20,22,23}$ Thus, experiments made with Pd films $2-16 \mathrm{~nm}$ thick on Si and Tl films in aqueous $0.5 \mathrm{M} \mathrm{H}_{2} \mathrm{SO}_{4}$ have shown that the hydrogen absorption characteristics of $\mathrm{Pd}$ were lost with prolonged storage or with extended electrochemical cycling, and thinner films produced oxidation and reduction voltammetric peaks similar to the $H$ peaks observed for Pt. This effect was more prominent for 2.2 and $3.9 \mathrm{~nm}$ Pd films, and a definite diffusion component which limits H sorption appears for those Pd films thicker than $8 \mathrm{~nm} .{ }^{22}$ A double peak related to $\mathrm{H}$ atom adsorption on $\mathrm{Pd}$ in acidic solution has also been observed, ${ }^{22,23}$ Recently, it has been demonstrated that cations of the supporting electrolyte have a different influence on the electrosorption and electro-oxidation of hydrogen either in or from $\mathrm{Pd}{ }^{57}$ Furthermore, the reversibility of $\mathrm{H}$-atom electroadsorption in acid has been confirmed for Pd overlayers on glassy carbon. ${ }^{58}$

The kinetics of the hydrogen electrode reaction on $\mathrm{Pd}$ has been earlier explained by a Volmer-Tafel mechanism, ${ }^{59,60}$ although it becomes much more complex including $\mathrm{H}$-atom adsorption and hydrogen absorption, as has

(57) Czerwinski, A.; Maruszezak, G.; Zelazowska, M.; Lancucka, M.; Marassi R.; Zamponi, S. J. Electroanal. Chem. 1995, 386, 207.

(58) Tateishi, N.; Hikozawa, K. Ya; Nishimura, K.; Suzuki, M. Iwanaga, Y.; Watanabe, M.; Enami, E.; Matsuda Y.; Takasu, Y. Electrochim. Acta 1991, 36, 1235.

(59) Enyo, M. In Comprehensive Treatise of Electrochemistry, Conway, B. E., Bockris, J. O’M., Yeager, E., Khan, S. U. M., White, R. E., Eds.; Plenum Press: New York, 1983; Chapter 5, p 241.

(60) Lewis, F. A. In Recent Progress in Surface Science; Danielli, J. F., Riddiford, A. C., Rosenberg, M. D., Eds.; Academic Press: New York, 1970; Vol. 3, p 71. 
been demonstrated for ultrafine Pd particles supported on flat glassy carbon ${ }^{19}$ and bubble formation at high current densities. ${ }^{60}$ For ultrafine Pd particles, ${ }^{16}$ hydrogen absorption occurred at more negative potentials than those for massive $\mathrm{Pd}$, making its interference with $\mathrm{H}$ atom adsorption almost negligible. $\mathrm{H}$-atom adsorption has also been observed on $\mathrm{Pd}$ overlayers on polycrystalline $\mathrm{Au} .^{21,23-25}$ It has been shown ${ }^{20}$ that the capability of $\mathrm{Pd}$ to absorb hydrogen starts with a Pd thickness of $3 \mathrm{ML}$, the $\mathrm{H} / \mathrm{Pd}$ ratio increasing with the amount of $\mathrm{Pd}$ and reaching 0.6 as a limiting value in acid solution. The change in shape of voltammograms with the thickness of the Pd film within the average thickness range $1 \mathrm{ML} \leq$ $<h>\leq 20 \mathrm{ML}$ supports the view that these peaks are associated with surface adsorption and desorption processes, while the broad features that shift with the sweep rate are due to bulk absorption and diffusion processes. It is thus entirely reasonable to expect the surface features to be prominent only when the amount of surface adsorption is large compared to that of absorption into the bulk, a condition that, as already reported in the literature, is fulfilled either for the thinnest films of $\mathrm{Pd}$ or Pd-black.

The enhancement of $\mathrm{H}$ atom electroadsorption processes on treated $\mathrm{Pd}$ is then consistent with the fractal characteristics of the Pd surface. In fact, in the presence of the $\mathrm{Pd}$ surface fractal overlayer, it is reasonable to expect that in the range of potential $0.3-0 \mathrm{~V}, \mathrm{H}$-atom surface processes rather than hydrogen absorption will be favored. A fractal surface with $D_{\mathrm{s}}=2.57$ implies that the ratio between $\mathrm{Pd}$ atoms at surface sites and Pd atoms in the bulk is largely increased as compared to a Euclidean $\left(D_{\mathrm{s}}\right.$ = 2) Pd surface.

Acknowledgment. This work was financially supported by the Consejo Nacional de Investigaciones Científicas y Técnicas of Argentina (CONICET) and the Comisión de Investigaciones Científicas de la Provincia de Buenos Aires.

LA9605302 